\title{
Épocas de aplicação do fertilizante nitrogenado no sistema convencional de semeadura de arroz irrigado ${ }^{1}$
}

\author{
Nitrogen fertilizer application times on conventional irrigated rice system \\ Victor Marzari ${ }^{2}$ Enio Marchezan ${ }^{3}$ Leandro Souza da Silva ${ }^{4}$ Sidnei Kuster Ranno ${ }^{5}$ \\ Fernando Machado dos Santos ${ }^{6}$ Edinalvo Rabaiolo Camargo $^{6}$
}

\begin{abstract}
- NOTA -
RESUMO

O nitrogênio (N) é um dos nutrientes mais importantes às plantas, mas a eficiência da adubação nitrogenada é reduzida pelos ciclos de oxidação e redução que ocorrem durante o cultivo de arroz irrigado por inundação, o que está relacionado com o modo de aplicação do fertilizante nitrogenado. O objetivo deste experimento foi avaliar diferentes épocas de aplicação e proporções da dose do fertilizante nitrogenado para o sistema convencional de produção de arroz irrigado em um Planossolo Hidromórfico no município de Santa Maria (RS). O delineamento experimental foi de blocos ao acaso com seis repetições e seis tratamentos: T1 - testemunha sem $N$; T2 - $45 \mathrm{~kg}$ $h a^{-1}$ de $\mathrm{N}$ no início do perfilhamento (IP) e $45 \mathrm{~kg} \mathrm{ha}^{-1}$ de $\mathrm{N}$ no início da diferenciação da panícula (IDP); T3 - $90 \mathrm{~kg} \mathrm{ha}^{-1}$ de N na semeadura; T4 - $45 \mathrm{~kg} \mathrm{ha}^{-1}$ de N na semeadura e $45 \mathrm{~kg} \mathrm{ha}^{-1} \mathrm{de}$ $\mathrm{N}$ no IP; T5 - $45 \mathrm{~kg} \mathrm{ha}^{-1}$ de $\mathrm{N}$ na semeadura e $45 \mathrm{~kg} \mathrm{ha}^{-1}$ de $\mathrm{N}$ no IDP; T6 - $30 \mathrm{~kg} \mathrm{ha}^{-1}$ de $\mathrm{N}$ na semeadura, $30 \mathrm{~kg} \mathrm{ha}^{-1}$ de $\mathrm{N}$ no IP e $30 \mathrm{~kg} \mathrm{ha}^{-1}$ no IDP, utilizando-se uréia como fonte de N. Foram avaliados a produção de matéria seca, o teor de $N$ no tecido e a quantidade de $N$ absorvido em 4 épocas (no IP; aos 15 dias após a primeira aplicação de $\mathrm{N}$ em cobertura; no IDP; e na floração) e o rendimento de grãos. Os parâmetros avaliados durante o ciclo variaram em função da época de coleta e das quantidades de $N$ aplicadas em cada tratamento. Entretanto, não houve diferença significativa no rendimento de grãos, inclusive para a testemunha, o que significa alta disponibilidade de $N$ no solo. Nestas condições, não há efeito

Palavras-chave: uréia, nitrogênio, parcelamento de N, eficiência da adubação.

ABSTRACT

Nitrogen $(N)$ is the most important nutrient to establish rice crop yield, but its dynamics on oxidations and reductions soil conditions in conventional flooded rice system can improve $N$ looses, that is related with time and quantities of $N$ application. The objective of this experiment was to evaluate different times and quantities of $N$ application in a conventional rice system in a "Planossolo Hidromórfico" (Typic Albaqualf) soil in Santa Maria, Rio Grande do Sul state. The experimental design was in random blocs with six replications and six treatments: $T 1$ - without $N$ application; $T 2-45 \mathrm{~kg} \mathrm{ha}^{-1}$ of $N$ in beginning of tillering (BT) and $45 \mathrm{~kg} \mathrm{ha}^{-1}$ of $\mathrm{N}$ at beginning of the

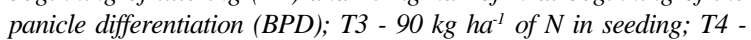
$45 \mathrm{~kg} \mathrm{ha}^{-1}$ of $N$ in seeding and $45 \mathrm{~kg} \mathrm{ha}^{-1}$ of N in BT; T5 - $45 \mathrm{~kg} \mathrm{ha}$ ${ }^{1}$ of $N$ in seeding and $45 \mathrm{~kg} \mathrm{ha}^{-1}$ of $N$ in BPD; T6 - $30 \mathrm{~kg} \mathrm{ha}^{-1}$ of $N$ in seeding, $30 \mathrm{~kg} \mathrm{ha}^{-1}$ of $N$ in BT and $30 \mathrm{~kg} \mathrm{ha}^{-1}$ in BPD, with urea as $N$ source. It was evaluate dry matter production, $N$ content, and $N$ absorbed in four evaluations (BT; 15 days after first $N$ application; $B P D$; and flowering), and grain yield. Parameters evaluated during rice cycle were different depending time and quantity of $N$ application in each treatment. However, there was not difference in rice grain yield among treatments, including without $N$ application, that appoint high soil nitrogen availability. In this condition, there is not effect of time and quantity of $N$ fertilizer.
\end{abstract} da época de aplicação e proporção da dose do fertilizante nitrogenado.
Key words: urea, nitrogen, $N$ splitting, and fertilizer efficiency.

\footnotetext{
${ }^{1}$ Marchezan, pesquisador do Conselho Nacional de Desenvolvimento Científico e Tecnológico (CNPq).

${ }^{2}$ Secretaria da Agricultura, Dona Francisca, RS, Brasil.

${ }^{3}$ Departamento de Fitotecnia, Centro de Ciências Rurais (CCR), Universidade Federal de Santa Maria (UFSM), 97105-900, Santa Maria, RS, Brasil. E-mail: emarch@ccr.ufsm.br. Autor para correspondência.

${ }^{4}$ Departamento de Solos, CCR, UFSM, Santa Maria, RS, Brasil.

${ }^{5}$ Pesquisador da Fundação MS, Maracaju, MS, Brasil.

${ }^{6}$ Programa de Pós-graduação em Agronomia, CCR, UFSM, Santa Maria, RS, Brasil.
} 
Dos nutrientes essenciais às plantas, 0 nitrogênio $(\mathrm{N})$ está entre os requeridos em maior quantidade, sendo considerado um importante fator para determinar o potencial de produção do arroz (MARUMOTO, 1986). A atual recomendação de nitrogênio em cobertura para o arroz irrigado no RS e SC preconiza aplicação em duas épocas, sendo a primeira no início do perfilhamento, e a segunda no início da diferenciação do primórdio floral (SOSBAI, 2003). Entretanto, a resposta do arroz a épocas de aplicação de $\mathrm{N}$ tem sido contraditória, com algumas indicando maior eficiência para aplicação na fase inicial da cultura, especialmente quando a disponibilidade do nutriente é baixa como em solos arenosos e de baixa matéria orgânica, e outros para aplicação próxima da fase reprodutiva, quando a planta tem sistema radicular bem desenvolvido e maior eficiência na absorção de N (SCIVITTARO \& MACHADO, 2004). Segundos estes autores, aplicação de $\mathrm{N}$ em cobertura próxima ao início da diferenciação do primórdio floral tem sido mais favorável, o que não exclui a possibilidade de melhores resultados com outras estratégias de aplicação.

Parte desta variação nos resultados de campo quanto às épocas de aplicação de fertilizantes nitrogenados pode ser devido ao fato de que o ciclo do $\mathrm{N}$ no cultivo do arroz está sujeito a uma complexa ordem de mecanismos regulatórios, que envolvem fatores físico-químicos, biológicos e, principalmente, reações redox (PATRICK JR., 1982; STEVENSON, 1982). De acordo com esses autores, o $\mathrm{N}$ originado da mineralização da matéria orgânica do solo ou da dissolução da uréia é mineralizado à formas inorgânicas, $\mathrm{NH}_{3}$ e $\mathrm{NH}_{4}^{+}$, que estão em equilíbrio químico dependente principalmente do $\mathrm{pH}$ do solo, conforme a reação $\mathrm{NH}_{3}+\mathrm{H}_{2} \mathrm{O} \leftrightarrow \mathrm{NH}_{4}^{+}+\mathrm{OH}^{-}$. Dessa forma, dependendo das condições edafoclimáticas, parte do N liberado pode ser perdida por volatilização da amônia. Em aerobiose, o $\mathrm{NH}_{4}^{+}$resultante desse equilíbrio pode ser retido na CTC do solo, absorvido pelas plantas, imobilizado na biomassa microbiana e sofrer nitritação (oxidação a $\mathrm{NO}_{2}^{-}$) seguida de nitratação (oxidação a $\mathrm{NO}_{3}^{-}$). Entretanto, com a entrada de água para a irrigação do arroz, a transformação do $\mathrm{NH}_{4}^{+}$em $\mathrm{NO}_{3}^{-}$é interrompida pela ausência de bactérias capazes de atuar nesse processo em condições anaeróbias, acumulando $\mathrm{NH}_{4}^{+}$, e o $\mathrm{NO}_{3}^{-}$ existente no solo poderá ser lixiviado, caso exista percolação da água no perfil do solo, ou reduzido, se utilizado como receptor final de elétrons pela biomassa microbiana anaeróbia, sofrendo denitrificação a $\mathrm{N}_{2} \mathrm{O}$ ou $\mathrm{N}_{2}$, que são formas voláteis e resultam em outro tipo de perda de $\mathrm{N}$ do solo.
Portanto, o $\mathrm{N}$ aplicado no solo via fertilizantes nitrogenados está sujeito a diversas transformações e a intensidade destas transformações define a disponibilidade de N às plantas. Dessa forma, a época de aplicação do fertilizante nitrogenado e a quantidade aplicada em cada época serão determinantes para intensidade de cada processo de perda e, conseqüentemente, estabelecer a eficiência da adubação (PENG et al., 1996, BREDEMEIER \& MUNDSTOCK, 2000). O objetivo deste estudo foi avaliar diferentes épocas de aplicação e proporções da dose do fertilizante nitrogenado para o sistema convencional, visando identificar a melhor estratégia para aplicação de N na produção de arroz irrigado.

O experimento foi realizado entre outubro de 2002 e abril de 2003 na área experimental do Departamento de Fitotecnia da Universidade Federal de Santa Maria, Rio Grande do Sul, em um Planossolo Hidromórfico Eutrófico arênico (EMBRAPA, 1999), cujas características químicas eram: matéria orgânica= 1,4\%; argila= 21\%; $\mathrm{pH}\left(\mathrm{H}_{2} \mathrm{O}\right)=4,9$; índice $\mathrm{SMP}=5,9$; $\mathrm{P}=4,8 \mathrm{mg} \mathrm{dm}^{-3}$; e $\mathrm{K}=40 \mathrm{mg} \mathrm{dm}{ }^{-3}$. O delineamento experimental foi de blocos ao acaso com seis repetições em parcelas de $2 \times 6 \mathrm{~m}$ e seis tratamentos: $\mathrm{T} 1$ - testemunha sem nitrogênio; T2 - $45 \mathrm{~kg} \mathrm{ha}^{-1}$ de N no início do perfilhamento (IP) e $45 \mathrm{~kg} \mathrm{ha}^{-1}$ de $\mathrm{N}$ no inicio da diferenciação da panícula (IDP); T3 - $90 \mathrm{~kg}$ ha $^{-1}$ de $\mathrm{N}$ na semeadura; T4 - $45 \mathrm{~kg} \mathrm{ha}^{-1}$ de $\mathrm{N}$ na semeadura e $45 \mathrm{~kg} \mathrm{ha}^{-1}$ de N no IP; T5 - $45 \mathrm{~kg} \mathrm{ha}^{-1}$ de $\mathrm{N}$ na semeadura e $45 \mathrm{~kg} \mathrm{ha}^{-1}$ de N no IDP; e T6 - 30 $\mathrm{kg} \mathrm{ha}^{-1}$ de $\mathrm{N}$ na semeadura, $30 \mathrm{~kg} \mathrm{ha}^{-1}$ de $\mathrm{N}$ no IP e 30 $\mathrm{kg} \mathrm{ha}^{-1}$ no IDP; utilizando-se uréia como fonte de N.

Para a instalação do experimento, a área sistematizada a 6 anos e cultivada anualmente com arroz irrigado, foi preparada com gradagem e a passagem de uma aplainadora do solo. A semeadura foi realizada no sistema convencional com semeadoraadubadora apropriada e espaçamento entre linhas de $0,17 \mathrm{~cm}$. O cultivar de arroz irrigado utilizado foi a IRGA 417 na densidade de $150 \mathrm{~kg} \mathrm{ha}^{-1}$ de sementes. A adubação com $\mathrm{P}$ e $\mathrm{K}$ foi realizada por ocasião da semeadura na quantidade de $60 \mathrm{~kg} \mathrm{ha}^{-1}$ de $\mathrm{P}_{2} \mathrm{O}_{5}$ e 80 $\mathrm{kg} \mathrm{ha}^{-1}$ de $\mathrm{K}_{2} \mathrm{O}$. Aos vinte dias após a semeadura, foi realizado o controle de plantas daninhas com os herbicidas propanil (1,4 kg i.a. ha $\left.{ }^{-1}\right)$ e quinclorac $(0,6$ kg i.a. ha-1) e, em seguida, efetuada a irrigação mantendo-se a lâmina de água de aproximadamente $10 \mathrm{~cm}$ até o final do ciclo da cultura. A adubação nitrogenada foi realizada com aplicação de uréia à lanço e de acordo com os tratamentos.

Em quatro épocas (no IP e antes da primeira aplicação de $\mathrm{N}$; aos 15 dias após a primeira aplicação de N em cobertura; na IDP; e na floração), foram 
avaliadas a produção de matéria seca com a coleta de plantas em um metro linear por parcela, determinado o teor de $\mathrm{N}$ no tecido de acordo com a metodologia descrita por TEDESCO et al. (1995), e calculado o N absorvido pela parte aérea das plantas. Ao final do cultivo, o rendimento de grãos foi determinado colhendo-se manualmente uma área útil de $6,8 \mathrm{~m}^{2} \mathrm{em}$ cada parcela sendo que, após a trilhagem e limpeza, a massa de grãos foi corrigida para $13 \%$ de umidade. Foi realizada a análise de variância $(\mathrm{P}<0,05)$ dos parâmetros avaliados e, quando significativo, as médias dos tratamentos foram comparadas pelo teste de Tukey $(\mathrm{p}<0,05)$.

A produção de matéria seca entre os tratamentos foi significativamente diferente nas três primeiras épocas de avaliação (Tabela 1). No início do perfilhamento e 15 dias após a primeira aplicação de $\mathrm{N}$ em cobertura, houve maior produção de matéria seca nos tratamentos que receberam a maior quantidade de uréia na semeadura e na primeira aplicação (T3 e T4), conseqüência da maior disponibilidade de $\mathrm{N}$ na fase vegetativa inicial da cultura proporcionada pela adubação. Já na floração, além de T3 e T4, o tratamento T6 também apresentou maior produção de matéria seca. Embora este tratamento tenha recebido doses equivalentes de $\mathrm{N}$ distribuídas nas três épocas de aplicação, as aplicações de $\mathrm{N}$ em cobertura permitiram produção de matéria seca equivalente ao arroz que recebeu as maiores doses na fase inicial de cultivo. Resposta da planta em matéria seca tem sido relacionada à quantidade de $\mathrm{N}$ aplicada para o arroz, o que reflete maior disponibilidade do nutriente, mas sua correspondente transformação em rendimento de grãos nem sempre tem sido obtida, o que pode estar relacionado com a perda de capacidade de utilização da radiação solar pelo auto-sombreamento das folhas e aumento da suscetibilidade a doenças fúngicas (SILVA et al., 2003; SCIVITTARO \& MACHADO, 2004).

O teor de nitrogênio no tecido da planta também foi influenciado pela época de aplicação do fertilizante nitrogenado, e os maiores valores estão associados as maiores quantidades de $\mathrm{N}$ aplicadas antecedendo a época da avaliação (Tabela 1). Cabe salientar que, na floração, o teor de $\mathrm{N}$ na testemunha sem aplicação de $\mathrm{N}$ não diferiu dos demais tratamentos com aplicação de N. Comportamento similar foi observado em relação à quantidade de nitrogênio absorvido pelas plantas (Tabela 1), que variou conforme o momento de aplicação e a dose em cada tratamento aplicadas antecedendo as épocas de avaliação. Entretanto, também não houve diferença na quantidade de $\mathrm{N}$ absorvida pelas plantas na floração
Tabela 1 - Produção de matéria seca, teor de $\mathrm{N}$ no tecido e quantidade de $\mathrm{N}$ absorvido em 4 épocas durante o ciclo e o rendimento de grãos de arroz irrigado com diferentes épocas de aplicação e proporção de doses do fertilizante nitrogenado no sistema de convencional de semeadura, Santa Maria, RS, safra 2002/2003.

\begin{tabular}{|c|c|c|c|c|c|}
\hline \multirow{2}{*}{ Tratamentos } & \multicolumn{5}{|c|}{ Época de avaliação } \\
\hline & \multicolumn{2}{|c|}{ IP } & 15 DAPN & IDP & FL \\
\hline & \multicolumn{5}{|c|}{ Matéria seca $\left(\mathrm{kg} \mathrm{ha}^{-1}\right)$} \\
\hline $\mathrm{T} 1$ & 203 & c & $400 \quad \mathrm{~d}$ & $4447^{\text {ns }}$ & $8400 \quad c$ \\
\hline $\mathrm{T} 2$ & $245 \quad c$ & c & 933 с & 4820 & $10533 \mathrm{~b}$ \\
\hline T3 & $1168 \mathrm{a}^{*}$ & & $2160 a^{*}$ & 4900 & 13307 a \\
\hline $\mathrm{T} 4$ & $968 \mathrm{ab}$ & & $1893 \mathrm{ab}$ & 4380 & $13882 a^{*}$ \\
\hline T5 & 752 b & & 1200 bc & 4447 & $10586 \mathrm{~b}$ \\
\hline T6 & 752 b & 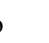 & $1413 \mathrm{c}$ & 4833 & $12940 \mathrm{a}$ \\
\hline Média & 681 & & 1333 & 4638 & 11608 \\
\hline \multirow[t]{2}{*}{$\mathrm{CV} \%$} & 21,0 & & 19,1 & 13,0 & 7,6 \\
\hline & \multicolumn{5}{|c|}{ Nitrogênio no tecido (g 100g-1 $)$} \\
\hline $\mathrm{T} 1$ & 2,02 & c & $4,12 \quad \mathrm{C}$ & $3,20 \mathrm{~b}$ & $2,17 \mathrm{ab}$ \\
\hline $\mathrm{T} 2$ & 2,01 & c & $6,63 a^{*}$ & $3,55 \mathrm{ab}$ & $2,38 a^{*}$ \\
\hline T3 & $2,54 \mathrm{ab}$ & & $2,84 \quad d$ & $2,70 \quad \mathrm{C}$ & $2,09 \mathrm{ab}$ \\
\hline $\mathrm{T} 4$ & $2,65 a^{*}$ & & $5,29 \mathrm{~b}$ & $2,69 \quad \mathrm{c}$ & $1,86 \mathrm{~b}$ \\
\hline T5 & $2,22 \mathrm{~b}$ & bc & 2,78 & $3,80 a^{*}$ & $2,26 \mathrm{a}$ \\
\hline T6 & 2,02 & c & $4,22 \quad \mathrm{c}$ & $3,52 \mathrm{ab}$ & $2,26 \mathrm{a}$ \\
\hline Média & 2,24 & & 4,31 & 3,24 & 2,17 \\
\hline \multirow[t]{2}{*}{$\mathrm{CV} \%$} & 4,2 & & 3,4 & 4,1 & 4,1 \\
\hline & \multicolumn{5}{|c|}{ Nitrogênio absorvido (kg ha-1) } \\
\hline $\mathrm{T} 1$ & 4,1 & c & $16,5 \quad \mathrm{c}$ & $142,5 \mathrm{ab}$ & $183,1 \mathrm{~b}$ \\
\hline $\mathrm{T} 2$ & 4,9 & c & $62,2 \mathrm{~b}$ & 169,7 a & $252,1 \mathrm{a}$ \\
\hline T3 & $29,4 a^{*}$ & & 61,0 b & $132,3 \mathrm{~b}$ & 278,0 a \\
\hline $\mathrm{T} 4$ & $25,7 \mathrm{a}$ & & 100,2 a & $117,7 \mathrm{~b}$ & 259,5 a \\
\hline T5 & $16,7 \mathrm{l}$ & $\mathrm{b}$ & $33,3 \quad c$ & 169,4 a & 240,1 a \\
\hline T6 & 15,2 & $\mathrm{~b}$ & 59,1 b & $170,6 \mathrm{a}^{*}$ & $293,4 a^{*}$ \\
\hline Média & 16,0 & & 55,4 & 150,4 & 251,0 \\
\hline \multirow[t]{2}{*}{$\mathrm{CV} \%$} & 19,7 & & 19,9 & 13,7 & 12,5 \\
\hline & \multicolumn{5}{|c|}{ Rendimento de grãos (kg ha-1) } \\
\hline $\mathrm{T} 1$ & \multicolumn{5}{|c|}{$8134^{\mathrm{ns}}$} \\
\hline $\mathrm{T} 2$ & \multicolumn{5}{|c|}{7926} \\
\hline T3 & \multicolumn{5}{|c|}{8293} \\
\hline $\mathrm{T} 4$ & \multicolumn{5}{|c|}{8102} \\
\hline T5 & \multicolumn{5}{|c|}{7790} \\
\hline T6 & \multicolumn{5}{|c|}{8203} \\
\hline Média & \multicolumn{5}{|c|}{8075} \\
\hline CV\% & \multicolumn{5}{|c|}{4,8} \\
\hline
\end{tabular}

*Médias seguidas pela mesma letra na coluna não diferem entre si pelo teste de Tukey $(\mathrm{P}<0,05)$.

${ }^{n s}$ não significativo pelo teste de Tukey $(\mathrm{P}<0,05)$.

IP - início do perfilhamento; 15 DAPN - 15 dias após a primeira aplicação de $\mathrm{N}$ em cobertura; IDP - inicio da diferenciação da panícula; FL - floração.

T1 - Testemunha sem N; T2 - $45 \mathrm{~kg} \mathrm{ha}^{-1}$ de N no IP e $45 \mathrm{~kg} \mathrm{ha}^{-1}$ de N no IDP; T3 - $90 \mathrm{~kg} \mathrm{ha}^{-1}$ de N na semeadura; T4 - $45 \mathrm{~kg} \mathrm{ha}^{-1}$ de $\mathrm{N}$ na semeadura e $45 \mathrm{~kg} \mathrm{ha}^{-1}$ de $\mathrm{N}$ no IP; T5 - $45 \mathrm{~kg} \mathrm{ha}^{-1}$ de $\mathrm{N}$ na semeadura e $45 \mathrm{~kg} \mathrm{ha}^{-1}$ de N no IDP; T6 - $30 \mathrm{~kg} \mathrm{ha}^{-1}$ de $\mathrm{N}$ na semeadura, $30 \mathrm{~kg} \mathrm{ha}^{-1}$ de $\mathrm{N}$ no IP e $30 \mathrm{~kg} \mathrm{ha}^{-1}$ no IDP.

Ciência Rural, v. 35, n. 5, set-out, 2005. 
entre as épocas de aplicação de nitrogênio, exceto para a testemunha que não recebeu nitrogênio.

Descontando as quantidades de $\mathrm{N}$ absorvidas pelos tratamentos com aplicação de uréia da quantidade absorvida pelas plantas sem aplicação do fertilizante, os valores variaram de 57 a $110 \mathrm{~kg}_{\text {de }} \mathrm{N} \mathrm{ha}^{-1}$, demonstrando efeito do $\mathrm{N}$ aplicado sobre a disponibilidade às plantas. Entretanto, o rendimento de grãos não foi influenciado pela época de aplicação do fertilizante nitrogenado (Tabela 1). Não houve, inclusive, resposta à aplicação de nitrogênio, o que pode ser atribuído à quantidade de nitrogênio absorvido pela testemunha (183,1 kg hä ${ }^{-1}$ ) e que deve ter sido suficiente para suprir as necessidades da planta no patamar de rendimento de grãos obtido. MACHADO \& DIAS (1985), avaliando a produtividade do arroz irrigado cv Bluebelle em experimento com 5 anos de duração, evidenciou ausência de resposta à aplicação de diferentes doses de N. Os autores atribuem a ausência de respostas e as variações de produtividade entre os anos ao fator clima, principalmente temperatura e radiação solar. Na literatura, são encontrados vários experimentos em que o arroz responde à adubação nitrogenada e vários outros que mostram ausência ou somente pequena resposta do arroz, indicando que outros fatores afetam sobremaneira a resposta da cultura à adubação nitrogenada, especialmente relacionados ao potencial de mineralização de $\mathrm{N}$ do solo e as condições climáticas durante o cultivo, e não somente o teor de matéria orgânica do solo ou a dose e época de aplicação do N (SCIVITTARO \& MACHADO, 2004; RHODEN, 2005).

Não houve diferença significativa no rendimento de grãos entre os tratamentos, inclusive para a testemunha, o que significa alta disponibilidade de $\mathrm{N}$ no solo. Nestas condições, não há efeito da época de aplicação e proporção da dose do fertilizante nitrogenado.

\section{REFERÊNCIAS}

BREDEMEIER, C.; MUNDSTOCK, C.M. Regulação da absorção e assimilação do nitrogênio nas plantas. Ciência Rural, Santa Maria, v.30, n.2, p.365-372, 2000.
EMBRAPA. Centro Nacional de Pesquisa de Solos. Sistema Brasileiro de Classificação de Solos. Brasília : Embrapa Produção de Informação; Rio de Janeiro: Embrapa Solos, 1999. 412p.

MACHADO, M.O.; DIAS, A.D. Resposta do arroz irrigado (cv. Bluebelle) ao nitrogênio, em cinco anos de cultivo. In: REUNIÃO DA CULTURA DO ARROZ IRRIGADO, 14., 1985, Pelotas/RS. Anais... Pelotas : EMBRAPA-CPATB, 1985. p.241-249.

MARUMOTO, T. Microbial nitrogen fixation and its availability to rice plants as revealed with the use of ${ }^{15} \mathrm{~N}$ in Japan. Japan Agricultural Research Quarterly, Yatabe, v.20, n.2, p.108-114, 1986.

PATRICK JR., W. H. Nitrogen transformations in submerged soils. STEVENSON, F.J. (ed). Nitrogen in agricultural soils. Madison: ASA, CSSA, SSSA, 1982. Cap.12, p.449-466.

PENG, S. et al. Increased N-use efficiency using a chlorophyll meter on high-yielding irrigated rice. Field Crops Research, v.47, p.243-252, 1996.

RHODEN, A.C. Potencial de mineralização anaeróbia do nitrogênio em solos de várzea do Rio Grande do Sul. 2005. 108f. Dissertação (Mestrado em Ciência do Solo) Curso de Pós-graduação em Ciência do Solo, Universidade Federal de Santa Maria.

SCIVITTARO, V.B.; MACHADO, M.O. Adubação e calagem para a cultura do arroz irrigado. In: GOMES, A.S.; MAGALHÃES JR, A.M. (eds). Arroz irrigado no sul do Brasil. Brasília, DF : EMBRAPA Informação Tecnológica, 2004. Cap.9, p.259-303.

SILVA, L.S. et al. Doses de nitrogênio e a resposta do arroz irrigado. In: CONGRESSO BRASILEIRO DE ARROZ IRRIGADO, 3., 2003, Balneário Camboriú. Anais... Balneário Camboriú: SOSBAI, 2003. 3p. CD-ROM.

SOSBAI. Sociedade Sul-brasileira de Arroz Irrigado. Arroz irrigado: recomendações técnicas da pesquisa para o Sul do Brasil. Balneário Camboriú : SOSBAI, 2003. 126p.

STEVENSON, F.J. Origin and distribution of nitrogen in soil. In: STEVENSON, F.J. (ed). Nitrogen in agricultural soils. Madison : ASA, CSSA, SSSA, 1982. Cap.1. p.1-42

TEDESCO, M.J. et al. Análise de solo, plantas e outros materiais. 2.ed. Porto Alegre : Departamento de Solos Universidade Federal do Rio Grande do Sul, 1995. 174p. (Boletim Técnico, 5). 